\title{
O GINECOLOGISTA OBSTETRA E A INTERNET
}

\section{THE GYNECOLOGISTS AND OBSTETRICIANS AND INTERNET}

\author{
Maria Luiza Toledo Leite Ferreira da Rocha ${ }^{1}$ \\ Ana Cristina d'Andretta Tanaka ${ }^{2}$
}

Rocha MLTLF; Tanaka ACA. O ginecologista obstetra e a internet. Rev Bras Crescimento Desenvolv Hum. 2009; 19(3): 412-425.

\section{Resumo:}

Objetivos: identificar a influência do uso da internet na prática e ambiente de trabalho médico e verificar como estas mudanças vêm acorrendo entre médicos ginecologistas e obstetras. Método: foram enviados 1.120 questionários para médicos ginecologistas e obstetras da cidade de São Paulo, dos quais retornaram 152, o correspondente a 13,6\% da amostra ou $6,1 \%$ do total dos médicos cadastrados na SOGESP. A análise quantitativa do comportamento do médico quanto ao uso da internet foi realizada por meio de proporções, médias, cálculos de desvios-padrão e do teste de associação de qui-quadrado. Através da técnica de Cluster Analysis, foram determinados 4 grupos segundo o perfil dos profissionais relacionado ao uso desta ferramenta. Resultados: não se observou relação de idade, sexo, locais de trabalho e desenvolvimento de apenas uma das especialidades Ginecologia ou Obstetrícia quanto à utilização da internet na prática médica. Observou-se uma tendência de uso mais freqüente entre médicos com doutorado. Quanto aos serviços médicos prestados por e-mail, receber e devolver exames foram as atividades mais realizadas pelos sujeitos da pesquisa. Conclusão: os ginecologistas obstetras pesquisados utilizam a internet na prática médica para própria atualização, para comunicação com pacientes ou para oferecer serviços às mesmas com diferentes assiduidades. Entretanto, este uso é ainda parcial, talvez relacionado ao receio de interferências negativas na relação com o paciente, além de preocupações quanto à implicações legais, éticas e principalmente econômicas relacionadas à prática profissional.

Palavras-chave: internet; ginecologia; obstetrícia; medicina; relação médico-paciente; informação; comunicação.

1 Médica ginecologista-obstetra. Doutor em Saúde Pública.

Correspondência para: Maria Luiza Toledo Leite Ferreira da Rocha. Rua Cristiano Viana, 441 cj.74/75. E-mail: malutl@terra.com.br

2 Professora Titular, Departamento de Saúde Materno Infantil da Faculdade de Saúde Pública da Universidade de São Paulo. Email: acdatana@usp.br

O artigo faz parte da Tese de Doutorado intitulada “O ginecologista obstetra e a internet. Uma realidade virtual?” defendida na Faculdade de Saúde Pública da Universidade de São Paulo; 2008. 


\begin{abstract}
:
Purpose: to identify the influence of the use of internet on medical practice and verify all changes about its use among gynecologists and obstetricians. Methods: a postal questionnaire was sent to 1.120 gynecologists and obstetricians of São Paulo city, 152 of which were returned, which represents a return rate of $13.6 \%$ and $6.1 \%$ of all the professionals of SOGESP. The quantitative analysis of the doctors ' behavior related to the use of the internet has been made by calculation of averages, proportions, standard deviations and the chisquared test. Four different groups have been determined by Cluster Analysis depending on the way this technology is used. Results: there was no relationship between age, sex and development of only Gynecology or Obstetrics related to use of internet. PhDs tend to use internet more. Wuth respect to the offning of medical services, receiving and sending exams through e-mail was the most common activity realized by the physicians. Conclusions: the gynecologists and obstetricians investigated in this research project use internet in their medical practice, for the updating of data collection, for communication with patients or offning their medical services by the Web. Although its use has been improved doctors are afraid of possible negative consequences regarding the physician-patient relationship and legal, economic and ethical consequences that this use may bring to clinical practice.
\end{abstract}

Key words: internet; gynecology; obstetrics; physician-patient relationship, information; communication.

\section{INTRODUÇÃO}

Diariamente, em consultórios e hospitais na América e em todo o mundo, profissionais da área médica estão se voltando à internet para se informar ou oferecer serviços e decisões mais embasadas a seus pacientes.

Do ponto de vista legal, o campo das leis médicas é construído sobre a relação médicopaciente, o que determina suas responsabilidades éticas. Mesmo em um mundo de cuidados médicos de alta tecnologia, a relação médico-paciente permanece essencial na prática médica. Com o desenvolvimento da internet, um indivíduo pode entrar em contato com um profissional e criar uma relação em espaço cibernético. Certamente, o diagnóstico médico e tratamento podem ser oferecidos via internet, entretanto, o espaço virtual altera a relação com o profissional médico, uma vez que elimina um elemento constante no atendimento que é a fisicalidade ${ }^{1}$.
O acesso à internet para a procura de informações sobre saúde tem crescido rapidamente para mais de 75-80\% quando comparado aos anos anteriores. Entretanto, menos de $10 \%$ dos pacientes se comunicam diretamente com seus provedores e médicos através de email. Em 2001, nos Estados Unidos, ocorreram apenas $9,2 \%$ contatos via e-mail ou consultas on line, 5,8\% em 2002 e 5,5\% em $2005^{2}$.

A comunicação entre médicos e pacientes pode ser de vários tipos: comunicações simples (prescrições, recebimento de exames) ou para interações mais detalhadas que incluam decisões clínicas. Revisões realizadas por alguns autores ${ }^{2}$ apontam que, com relação às simples trocas de e-mails, os pacientes reclamam da questão do tempo decorrido entre o encaminhamento da mensagem e a resposta dos profissionais, além da questão de segurança, confidencialidade dos assuntos discutidos, e da abordagem inapropriada para solução de questões urgentes ou delicadas nas quais seri- 
am mais apropriadas as consultas tradicionais face-a-face.

A introdução de serviços on line em clínica médica acarreta diminuição no volume de pacientes, conferindo mais disponibilidade à equipe para atendimentos de urgência. Muitos médicos apreciam a natureza assincrônica das mensagens via Web, pois permitem que os pacientes entrem em contato segundo sua conveniência e os profissionais respondam quando têm tempo ${ }^{3}$.

A aplicação das tecnologias em informática vem causando um profundo impacto no meio ambiente de trabalho do médico, na maneira como o mesmo presta seus serviços, alterações no processo de aprendizado dos profissionais e estabelecimento de uma nova relação "médico-internet-paciente". Assim, o objetivo é identificar a influência do uso da internet na prática e ambiente de trabalho médico e verificar como estas mudanças vêm ocorrendo entre médicos ginecologistas e obstetras.

\section{MÉTODO}

Trata-se de um estudo descritivo, envolvendo médicos ginecologistas e obstetras residentes no município de São Paulo, cadastrados na Sociedade de Obstetrícia e Ginecologia do Estado de São Paulo (SOGESP) até 15 de setembro de 2006, que foram investigados sobre o uso da internet na prática médica através de questionários enviados por correio. Este cadastro continha 2.721 profissionais. Para o sorteio da amostra considerou-se 2.491 médicos com CEP do referido município adequadamente informado. A composição da amostra foi por sorteio; sistematizada e ordenada por CEP. Foram enviadas 1.120 correspondências para médicos associados à SOGESP.

Cada correspondência enviada continha um questionário, um envelope para o re- torno, selado previamente com o endereço da pesquisadora e uma carta de apresentação, bem como termo de consentimento livre e esclarecido sobre as propostas e intenções da pesquisa. Foram recebidos e analisados 152 questionários que chegaram no período de três meses. Para a distribuição em grupos através da Cluster Analysis ${ }^{4}$ foram excluídos 13 questionários por preenchimento incompleto, que não foram devolvidos aos pesquisados, haja vista que os mesmos foram enviados sem a identificação.

O questionário foi composto de 14 questões, de Q1 a Q14, muitas delas de múltipla escolha e que, portanto apresentaram soma dos percentuais maior que 100. Foram incluídas questões abertas para se obter um melhor detalhamento das opiniões dos profissionais com relação aos diferentes aspectos abordados. Esta pesquisa foi aprovada pelo Comitê de Ética em Pesquisa da Faculdade de Saúde Pública da Universidade de São Paulo com protocolo número 1365.

A análise quantitativa dos respondentes quanto ao uso da internet foi realizada por meio de proporções, médias e cálculos de desvios padrão. A comparação entre o grupo de médicos que utilizava a internet na prática médica e o grupo que não a utilizava, sua distribuição segundo local, tipo de atendimento, natureza do serviço, recursos da internet utilizados, formação ou titulação acadêmica, idade, sexo e tempo de formado foi feita através do teste de associação do qui-quadrado ${ }^{5}$.

Com a finalidade de descrever o perfil dos médicos ginecologistas e obstetras quanto ao uso da internet foi utilizada a técnica de Cluster Analysis ${ }^{4}$, com o objetivo de se agrupar os médicos em dois ou mais grupos baseados na similaridade quanto às características de uso da internet, formando grupos homogêneos internamente e heterogêneos entre si.

O procedimento Hierarchical Cluster ${ }^{4}$ utilizado permitiu se agrupar indivíduos por 
meio de um método de aglomeração de forma que, inicialmente, cada indivíduo era um grupo. No passo seguinte, os grupos mais próximos foram unidos formando novos grupos, e assim sucessivamente, até se obter um único grupo.

Para se identificar as variáveis que caracterizavam cada grupo, foi utilizado o teste qui-quadrado para independência ${ }^{5}$ entre duas variáveis qualitativas, ou seja, as variáveis quanto ao uso da internet versus o grupo.

\section{RESULTADOS}

Dos 1.120 questionários enviados, para 571 mulheres (51\%) e 549 homens (49\%), foram respondidos 13,6\% ( $\mathrm{n}=152)$. Destes, $48 \%(\mathrm{n}=70)$ eram de mulheres e 52\% ( $\mathrm{n}=75)$ de homens; 7 questionários não informaram o sexo (Q1).

Entre os 152 respondentes, a idade variou conforme especificado na Tabela 1.

O tempo médio de formação dos profissionais (Q2), variou conforme a Tabela 2.

Tabela 1: Distribuição da idade dos respondentes (anos) segundo sexo. Município de São Paulo, 2007.

\begin{tabular}{lcccccc}
\hline \multirow{2}{*}{ Sexo } & $\mathbf{N}$ & $\mathbf{\%}$ & \multicolumn{4}{c}{ Idade (anos) } \\
& & & Mínima & Média & Mediana & Máxima \\
\hline Feminino* & 67 & 45 & 28 & 43 & 43 & 65 \\
Masculino** & 73 & 50 & 27 & 50 & 50 & 73 \\
Não informado & 7 & 5 & 39 & 46 & 41 & 61 \\
Total & 147 & 100,0 & 27 & 46 & 46 & 73 \\
\hline
\end{tabular}

Não informado $=7$ respondentes sem informação do sexo

*excluídas 3 mulheres sem informação de idade

**excluídos 2 homens sem informação de idade

Tabela 2: Distribuição do tempo de formação (anos) segundo sexo. Município de São Paulo, 2007.

\section{Idade (anos)}

\begin{tabular}{|c|c|c|c|c|c|c|}
\hline Sexo & $\mathbf{N}$ & $\%$ & Mínima & Média & Mediana & Máxima \\
\hline Feminino & 70 & 46 & 5 & 20 & 21 & 41 \\
\hline Masculino & 75 & 49 & 4 & 25 & 25 & 50 \\
\hline Não informado & 7 & 5 & 14 & 22 & 18 & 36 \\
\hline Total & 152 & 100,0 & 4 & 23 & 23 & 50 \\
\hline
\end{tabular}

Não informado $=7$ respondentes sem informação do sexo 
Quando analisadas as atividades exercidas em Ginecologia/Obstetrícia, e o desenvolvimento de outras atividades entre os 152 respondentes (Q3), observou-se que a maioria deles $(\mathrm{n}=98)$ era ginecologista e obstetra $(64 \%)$, sendo que $18 \%(n=28)$ exerciam também outras atividades. Seis por cento dos profissionais ( $\mathrm{n}=9)$ exerciam somente Ginecologia e $5 \%(n=7)$, apenas Obstetrícia. Dois por cento dos profissionais $(n=3)$ exerciam Obstetrícia associada a outras atividades, enquanto $3 \%(n=5)$ praticavam Ginecologia associada a outras atividades.

Em relação à formação médica após a graduação (Q4), 12 profissionais não responderam esta questão. Dos 140 médicos analisados, $63 \%(n=88)$ fizeram especialização, 31\% ( $n=$ 44) tinham doutorado e $19 \%(n=27)$ mestrado.

Quanto à distribuição dos médicos segundo local de trabalho (Q5), apenas 1 profis- sional não respondeu esta questão. Portanto, dos 151 respondentes, observou-se que 91\% $(n=138)$ atendiam em consultórios particulares, $49 \%(n=71)$ dos médicos atendiam em hospitais particulares, 40\% ( $n=61)$ em hospitais públicos, 27\% ( $\mathrm{n}=40)$ em Unidades Básicas de Saúde, 20\% $(n=30)$ faziam diagnose clínica, $18 \%(\mathrm{n}=27)$ realizavam atendimento de urgência em hospitais públicos e 14\% ( $\mathrm{n}=21)$ atendimento de urgência em hospitais particulares. Os médicos exerciam suas atividades, em média, em 3 locais sendo frequentemente em consultório, UBS e hospital público.

A análise do uso da internet na prática médica (Q6) mostrou que eles a utilizavam em média para 4,3 finalidades, principalmente para obter informações sobre questões de saúde e ter acesso à base de dados como pode ser observado na Figura 1.

Figura 1: Percentagem das finalidades do uso da internet entre os médicos. Município de São Paulo, 2007.

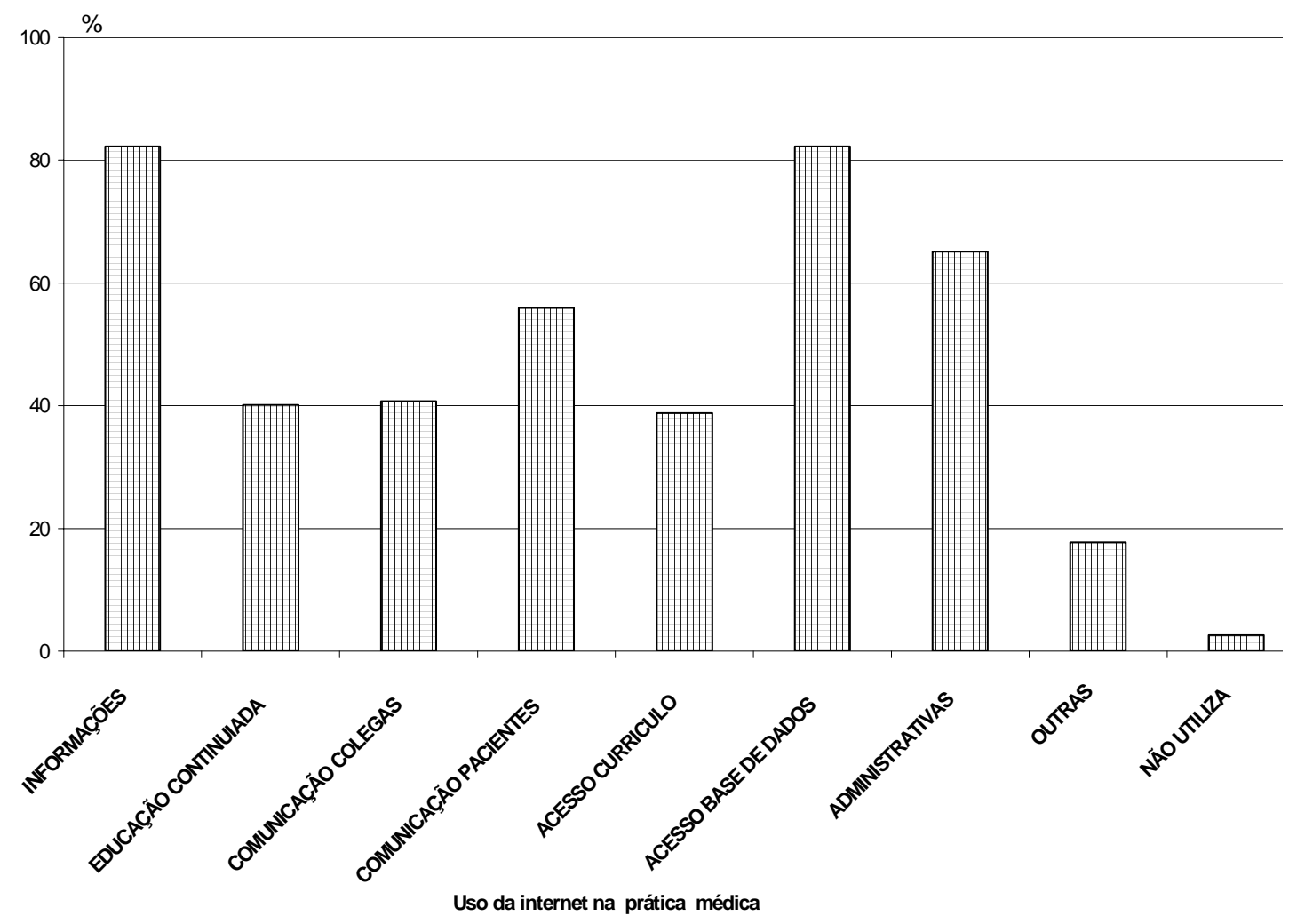


Em relação à peridiocidade de uso da internet $(\mathrm{Q} 7)$, apenas 3\% $(\mathrm{n}=4)$ não responderam esta questão e $5 \%(n=8)$ referiram não utilizá-la. Portanto, dos 140 profissionais que a utilizavam 56\% ( $\mathrm{n}=83)$ o faziam diariamente, $28 \%(\mathrm{n}=42)$ semanalmente, $7 \%$ $(n=11)$ eventualmente, e 3\% $(n=4)$ a utilizavam mensalmente.

Quanto à peridiocidade do uso da internet e o local de trabalho o teste qui-quadrado entre as variáveis local de trabalho (privado ou público) e o grupo demonstrou que não houve associação. Portanto não foi possível se estabelecer correlação.

Dos 147 médicos que referiram em Q8 utilizar a internet como ferramenta de trabalho, $52 \%(\mathrm{n}=77)$ o faziam para receber resultados de exames e 35\% $(n=51)$ não disponibilizavam serviços aos pacientes por internet (Figura 2).

Dos 51 médicos que responderam não disponibilizar "NENHUM" serviço por internet em Q8, 10 afirmaram que a utilizavam para comunicação com os pacientes em Q6, demonstrando incoerência nas respostas. Da mesma forma, observou-se em Q7 que 8 profissionais responderam não utilizar a internet enquanto, em Q8, apenas 5.

Quanto à clientela que mais solicitava o contato por internet (Q9), observou-se que predominaram as pacientes particulares, 67\% $(\mathrm{n}=98)$, seguida das pacientes conveniadas ( $\mathrm{n}=56), 39 \%$ e que nenhuma paciente de serviço público os solicitava.

Quanto à interferência da internet na dinâmica da consulta (Q10), apenas 135 profissionais responderam esta questão. Destes, $46 \%$ $(n=62)$ afirmaram que o uso da internet facilitava sua dinâmica e $36 \%(n=48)$ que seu uso não interferia na mesma. Apenas $17 \%(n=23)$ dos profissionais referiram que a internet a dificultava e $1 \%(n=2)$ respondeu que esta poderia tanto dificultar quanto facilitar a mesma.

Em relação à interferência da internet na relação médico-paciente (Q11), apenas143 a responderam. Destes, 30\% $(n=43)$ referiram

Figura 2: Percentagem de serviços disponíveis aos pacientes. Município de São Paulo, 2007.

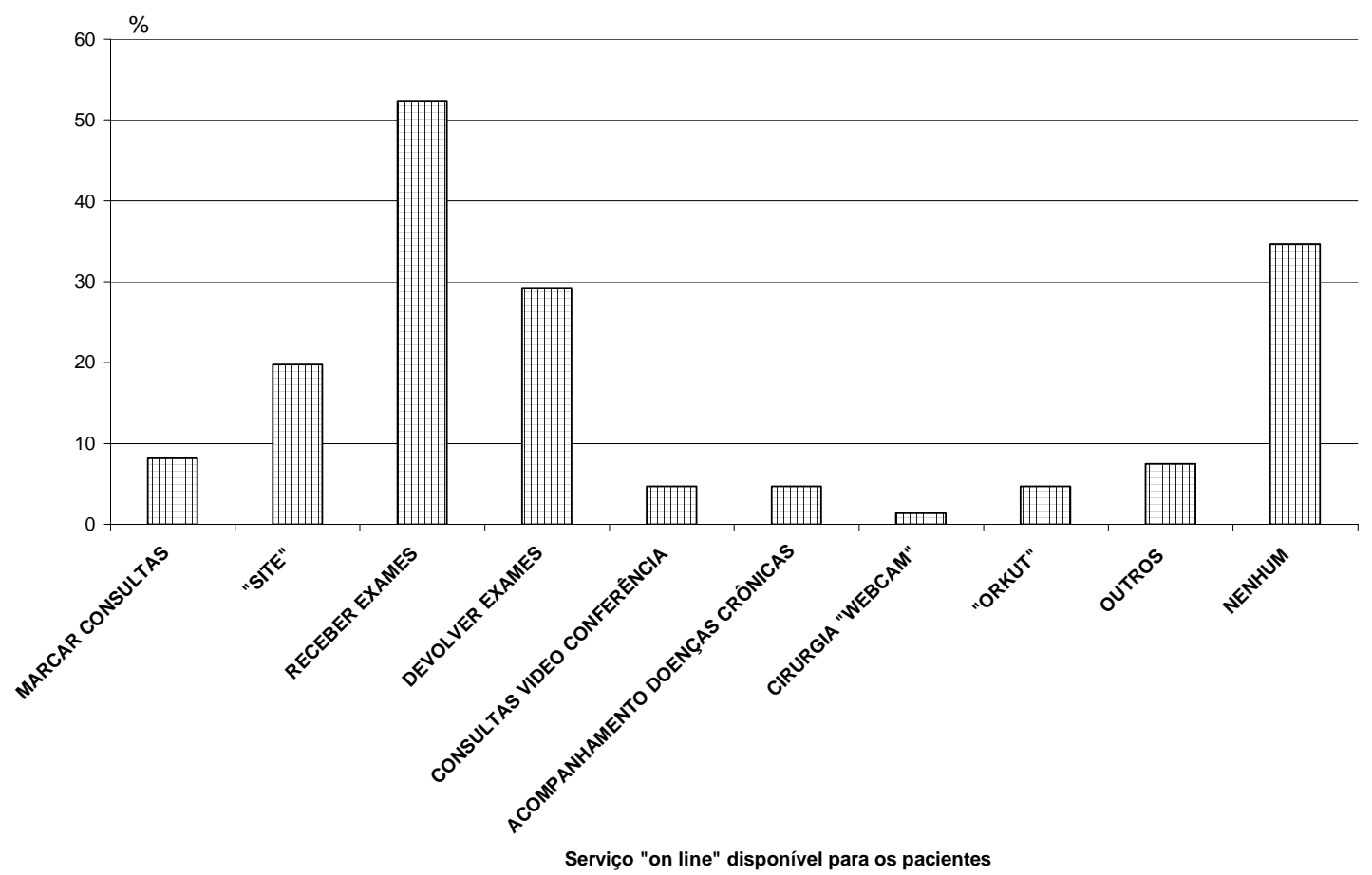


que as informações disponíveis na internet interferiam negativamente, $27 \%(n=38)$ interferiam positivamente, $24 \%$ ( $n=34)$ não interferiam e 19\% ( $n=28)$ interferiam positiva e negativamente na relação entre eles.

Quanto às implicações do uso da internet na prática médica para diferentes finalidades (Q12), 144 médicos responderam esta questão conforme a Tabela 3.

Ao serem indagados se a introdução da internet na Medicina mudaria a prática médica (Q13), obteve-se 78\% ( $\mathrm{n}=119)$ de respostas positivas. Dos 152 questionários, 9\% $(n=13)$ não a responderam e 13\% (n = 20) apresentaram respostas negativas.

Sobre o não uso da internet na prática médica (Q14), pergunta esta que deveria ter sido respondida apenas pelos 5 médicos que referiram não utilizá-la em Q8, observou-se que, além destes, 17 profissionais a responderam $(n=22)$. Os motivos que mais freqüentemente os levavam a não utilizá-la podem ser verificados na Figura 3.

Os grupos de médicos obtidos pela técnica de Cluster Hierárquico, segundo similaridades no uso da internet, definidas através

Tabela 3: Percentagem das implicações do uso da internet na prática médica. Município de São Paulo, 2007.

\begin{tabular}{lcccccccc}
\hline \multirow{2}{*}{ Finalidades } & \multicolumn{9}{c}{ Éticas licações** } & \multicolumn{2}{c}{ Legais } & \multicolumn{2}{c}{ Econômica } & \multicolumn{2}{c}{ Não tem } \\
& N* & $\mathbf{\%}$ & $\mathbf{N}$ & $\mathbf{\%}$ & $\mathbf{N}$ & $\mathbf{\%}$ & $\mathbf{N}$ & $\mathbf{\%}$ \\
\hline Receber exames & 52 & 36 & 24 & 17 & 55 & 38 & 52 & 36 \\
Prescrever medicamentos & 100 & 69 & 63 & 44 & 31 & 21 & 15 & 10 \\
Tirar dúvidas/orientações & 53 & 37 & 33 & 23 & 35 & 24 & 64 & 44 \\
Agendar consultas & 9 & 6 & 6 & 4 & 42 & 29 & 89 & 62 \\
Acompanhamento de & & & & & & & & \\
pacientes crônicos & 82 & 57 & 55 & 38 & 40 & 28 & 28 & 19 \\
Outras finalidades & 8 & 6 & 4 & 3 & 4 & 3 & 4 & 3 \\
\hline
\end{tabular}

*Percentagem calculada sobre 144 profissionais que responderam a Q12

** Questão de múltipla escolha

Figura 3: Percentagem dos motivos do não uso da internet. Município de São Paulo, 2007

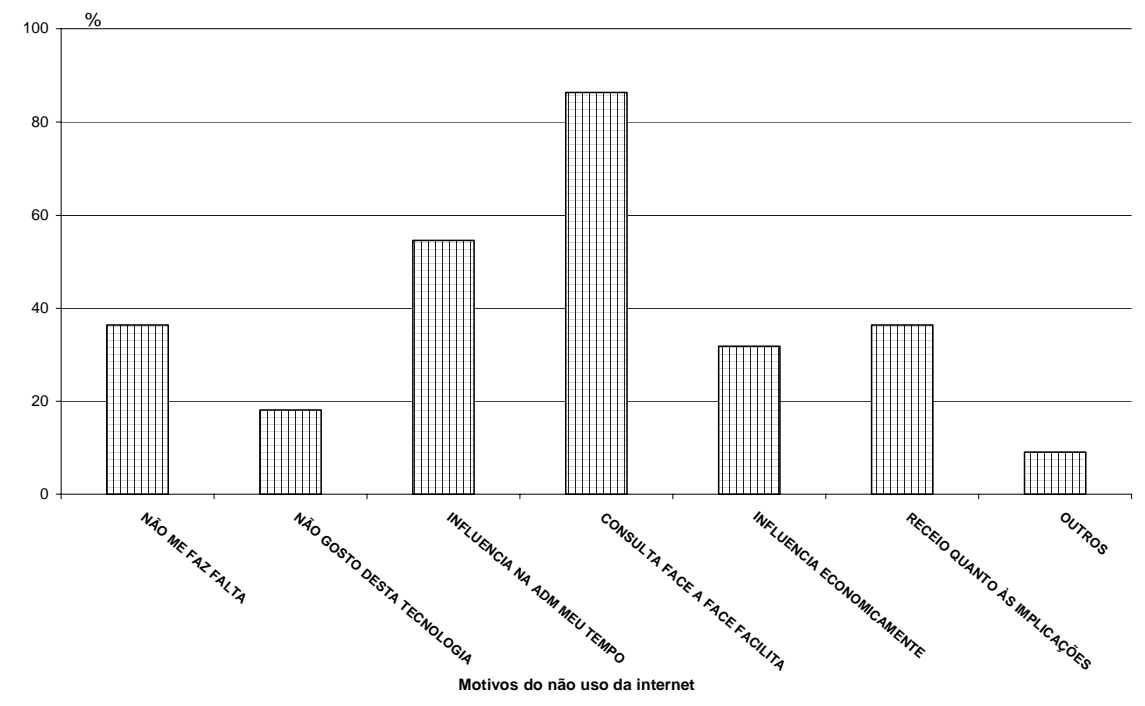


do teste qui-quadrado para independência e valores de $\mathrm{p}(<0,05)^{5}$ apresentaram a seguinte distribuição:

O grupo G1 nominado de não usuários na prática médica foi composto por 29 profissionais e correspondeu a $21 \%$ da amostra. Este grupo caracterizou-se por ginecologistas e obstetras predominantemente mulheres (66\%) ( $\mathrm{n}=$ 19), com idade média de 47 anos, tempo médio de formado de 24 anos e que não utilizavam a internet na prática médica. Quando a utilizavam $(n=25)$, seu uso era eventual, raramente semanal ou mensal (86\%) e, aparentemente, não relacionado à prática profissional, uma vez que 90\% dos indivíduos deste grupo $(\mathrm{n}=26)$ responderam que não disponibilizavam nenhum serviço aos seus pacientes, e que também sua clientela não solicitava o uso desta ferramenta. Vinte e um profissionais (72\%) julgavam que a internet interferia negativamente na relação médico paciente, o que poderia demonstrar preconceito. Quarenta e oito por cento dos profissionais deste grupo $(n=14)$ responderam que a consulta face-a-face facilitava o diagnóstico e a adesão ao tratamento, 31\% $(\mathrm{n}=9)$ que o uso desta ferramenta influenciava na administração do tempo com as consultas e $21 \%(\mathrm{n}=6)$ demonstraram preocupações quanto às implicações econômicas e legais que seu uso poderia acarretar.

O grupo GII, definido como usuários sem preconceitos, mas com restrições foi o de maior expressão numérica, composto por 66 profissionais que corresponderam a $48 \%$ da amostra. Caracterizou-se por $60 \%$ de ginecologistas e obstetras do sexo masculino (n = 40), com idade média de 44 anos e formados em média há 20 anos. Quarenta e nove destes profissionais (74\%) utilizavam a internet diariamente, para se comunicarem com colegas $(53 \%)(n=35)$, ou com pacientes $(70 \%)(n=46)$; a grande maioria $(n=58)$ a utilizava para acessar bases de dados bibliográficos(88\%). Das atividades realizadas via internet, receber e devolver exames preenche- ria $76 \%(n=50)$ e $50 \%(n=33)$ respectivamente. Neste grupo não se observaram preocupações quanto às questões éticas, econômicas ou legais, exceto quanto à prescrição de medicamentos, que segundo $74 \%$ deles $(\mathrm{n}=$ 49) poderia implicar questões éticas. Quanto à influência na relação médico-paciente, estes profissionais apresentaram opiniões opostas. Aproximadamente $56 \%$ deles $(n=37)$ achavam que as informações trazidas da internet pela paciente interferiam positivamente. Quanto à influência na dinâmica das consultas, $76 \%$ dos respondentes deste grupo $(n=50)$ consideraram que as informações obtidas previamente facilitavam, referindo sua influência como positiva. Oitenta e sete por cento destes profissionais $(n=57)$ referiram que as pacientes que mais solicitavam o uso desta ferramenta eram as clientes particulares e $65 \%$ deles $(n=43)$ não viam implicações em se agendar consultas via internet.

Sequenciando, constituiu-se o grupo GIII, nominado de usuários da internet com muitas restrições. Composto por 28 profissionais que correspondeu a $20 \%$ da amostra, este grupo caracterizou-se por ginecologistas e obstetras de ambos os sexos, com idade média de 42 anos, tempo médio de formado de 19 anos e que utilizavam a internet para comunicação com colegas $(54 \%)(n=15)$, com pacientes $(68 \%)(n=19)$, para acessar bases de dados bibliográficos $(86 \%)(n=24)$ e também para outras finalidades $(43 \%)(n=12)$. Vinte e cinco por cento destes profissionais disponibilizavam sites às suas pacientes. A metade deles $(54 \%)(n=15)$ achava que os conhecimentos adquiridos pela paciente via internet não interferiam na dinâmica da consulta e a grande maioria $(\mathrm{n}=21)$ afirmou que receber exames implicaria questões econômicas $(75 \%)$. Um número menor $(n=11)$ também acreditava que tal procedimento poderia implicar questões legais (39\%).

Quanto às prescrições de medicamentos, $68 \%$ dos profissionais $(\mathrm{n}=19)$ acreditavam que 
tal conduta implicaria questões legais. Para $68 \%$ deles $(\mathrm{n}=19)$, tirar dúvidas poderia implicar questões legais, econômicas (39\%) (n = $11)$ ou éticas $(86 \%)(n=24)$. O acompanhamento de doentes crônicos poderia implicar questões éticas para $89 \%$ deles $(n=25)$, assim como questões legais, na opinião de $71 \%$ ( $\mathrm{n}=$ 20). Cinqüenta e sete por cento destes médi$\cos (n=16)$ achavam que agendar consultas por internet implicaria questões econômicas e para $14 \%$ deles $(n=4)$, legais. Este grupo foi muito expressivo quanto às práticas médicas on line, entretanto, foi o que mais apresentou preocupações com questões éticas, legais ou econômicas.

Por fim, compôs-se o grupo GIV, o qual foi nominado de usuários sem preconceitos e sem restrições. Composto por 16 profissionais que correspondeu a $11 \%$ da amostra, foi o grupo numericamente menos representativo, mas o mais expressivo quanto às práticas médicas via internet sem preocupações com questões éticas, legais ou econômicas. Este grupo caracterizou-se por ginecologistas e obstetras de ambos os sexos, com idade média de 51 anos e formados em média há 27 anos. Dos quatro grupos, é o que reuniu profissionais com mais idade e com maior tempo de formado. Sessenta e três por cento destes $(\mathrm{n}=10)$ utilizavam a internet diariamente, $69 \%(\mathrm{n}=11)$ para comunicação com pacientes e principalmente recebimento de exames. Neste grupo, 63\% dos médicos tinham doutorado $(\mathrm{n}=10)$ e a grande maioria $(88 \%)(n=14)$ utilizava a internet para consultas às bases de dados bibliográficos. Para $75 \%$ destes profissionais $(n=12)$ a cliente particular era a que mais requisitava os serviços via internet. Na opinião de $88 \%$ deles $(n=14)$, $81 \%(n=13)$ e $50 \%(n=8)$, respectivamente, receber exames, tirar dúvidas e acompanhar pacientes crônicos, não tinham implicações. Segundo $75 \%$ destes $(\mathrm{n}=12)$, o acesso à internet pelas pacientes e as informações por elas obtidas não interferiam na dinâmica da consulta. Para 56\% ( $=9$ ), seu uso interferia positivamente na relação médico-paciente e as atividades de se prescrever medicamentos e agendar consultas também não tinham quaisquer implicações segundo 38\% $(n=6)$ e $69 \%$ $(\mathrm{n}=11)$, respectivamente.

\section{DISCUSSÃO}

Ao se analisar o uso da internet conforme o sexo, observou-se que no grupo GI, mais da metade (66\%) eram mulheres, freqüência esta não observada nos demais grupos. Isto poderia remeter a hipóteses de que as mulheres usariam menos esta ferramenta, entretanto, os grupos GII e GIV eram compostos igualmente por homens e mulheres. Portanto, tais dados não concordaram com artigos anteriores ${ }^{6,7}$ controversos, que observaram que profissionais do sexo feminino e masculino, respectivamente, utilizavam a internet mais frequentemente.

Quanto à idade, quando comparados o grupo GI com os demais grupos, observou-se que a média de idade dos profissionais do primeiro foi de 47 anos, enquanto a idade média dos últimos foi de 45. Portanto, a variável idade não se demonstrou relevante quanto ao uso desta ferramenta de trabalho. Desta forma, este estudo não concordou com a hipótese de que usuários de internet poderiam compor um grupo de profissionais mais jovens e com menos tempo de formados defendida por outros autores ${ }^{8,9}$. Os resultados se aproximaram dos dados de estudo anterior ${ }^{7}$ que encontrou uma idade média de 49-50 anos ou menos entre os médicos usuários e também observou correlação negativa entre uso da internet entre profissionais mais velhos e da prática privada. Em contradição, as pesquisas revisadas pelos autores demonstraram que as páginas da Web sobre educação médica vinham sendo utilizadas por preceptores de residentes e estudantes de serviços universitários mais velhos. 
Ao se avaliar a graduação profissional e a titulação acadêmica dos respondentes (Q4), observou-se que estas variáveis não apareceram como fator discriminatório entre uso ou não da internet na prática médica, entretanto, observou-se um discreto predomínio de profissionais com doutorado no grupo GIV (63\%). Em concordância com esta análise, no grupo GI, a variável doutorado ou mestrado não se apresentou expressiva, apesar de existirem poucos doutores neste grupo. Também em GIII, cujos profissionais apresentaram muitas preocupações com questões legais, econômicas e éticas, a presença de profissionais com pósgraduação nível mestrado ou doutorado foi pequena. Resumindo, com relação à titulação acadêmica, os dados mostraram que os grupos que reuniram profissionais com menor restrição ao uso desta ferramenta agruparam também a maior percentagem de doutores (GII e GIV).

Estes dados diferem de estudo ${ }^{10}$ que apontou que na área acadêmica, 94,9\% dos docentes de pós-graduação utilizavam a internet para suas atividades acadêmico-científicas; e grande parte o fazia com propósitos de comunicação, acessando diariamente o correio eletrônico. A discordância entre estas observações e os dados desta pesquisa, deve-se, provavelmente, ao fato de nem todos os profissionais com titulação acadêmica (mestrado e doutorado) seguirem carreira como docentes.

Considerando-se que os profissionais trabalhavam em média, em 3 locais, nas áreas pública e privada, que eram as clientes particulares que mais solicitavam o uso da internet, e que muitos serviços públicos não são equipados tecnologicamente, tentou-se verificar se a freqüência de uso da internet seria menor entre os médicos que atuassem em serviços públicos, mas não se verificou tal associação não sendo possível relacionar local de trabalho e uso da internet.

Observou-se que a grande maioria dos médicos usava a internet para obter informa- ções sobre questões de saúde e ter acesso à base de dados. Tais resultados concordaram com pesquisa prévia ${ }^{8}$ segundo a qual $66 \%$ dos médicos canadenses, usavam a internet em sua prática médica como um instrumento de obtenção de informação e para obter suporte aos tratamentos direcionados a seus pacientes.

Quanto à periodicidade de uso da internet na prática médica, a grande maioria (84\%) o fazia diariamente ou semanalmente e apenas 5\% não a utilizava o que demonstrou o uso freqüente da internet entre ginecologistas obstetras desta amostra.

Observou-se que metade (52\%) dos 147 profissionais que referiram utilizar a internet em Q8, recebiam e avaliavam resultados de exames de suas pacientes. Esta prática que despertou preocupações econômicas e éticas em apenas 38\% e 36\% dos respondentes (Q12), poderia agilizar o diagnóstico e tratamento das mesmas, uma vez que dispensa a consulta de retorno. Isto, por um lado, poderia ser benéfico, pois economizaria os gastos e o tempo que a mesma disporia para se deslocar ao consultório. Por outro lado, poderia implicar menos ganho ao médico que, dependendo do tempo decorrido entre a consulta e o retorno, cobraria a segunda consulta.

Excetuando-se o recebimento e devolução de exames, o fato de poucos profissionais da amostra disponibilizarem serviços tais como marcações de consultas, consultas ou cirurgias por videoconferência, participação em salas médicas (Orkut) ou sites com informações médicas para as pacientes, demonstrou pouco envolvimento desta classe com os recursos desta nova tecnologia. Tais dados concordam com a análise de literatu$\mathrm{ra}^{2}$ segundo a qual, apesar do crescimento do acesso à internet, o número de atividades realizadas através da mesma, a comunicação entre médicos e pacientes via internet e, principalmente, a ocorrência de consultas via email são ainda poucas e não apresentaram aumentos expressivos. 
Talvez o motivo que levaria esses profissionais a utilizarem apenas estes recursos e não consultas on line seria o mesmo observado por outro autor ${ }^{11}$ que afirma ser o grau de resolução destas muito aquém dos primeiros cuidados tradicionalmente realizados. Em discordância destes dados, outros autores ${ }^{12}$ afirmam que muitas consultas on line, sem qualquer contato prévio com o médico têm sido cada vez mais freqüentes.

Os profissionais pesquisados apresentaram opiniões e preocupações nitidamente diversas sobre o uso da internet na prática profissional, mesmo quando pertencentes a um mesmo grupo como se verificou nos comentários da questão aberta (Q10) sobre a influência do uso da internet na dinâmica da consulta. Apesar de ter sido possível a distribuição da população estudada nos quatro grupos, notouse que essas respostas foram extremamente parecidas entre eles. A heterogeneidade das respostas dentro de um mesmo grupo, também foi evidente. De fato, se para um profissional, ter uma paciente mais informada, crítica e questionadora facilita a dinâmica da consulta, para outro, este fato pode ser negativo, dificultando a mesma.

Os dados de literatura relacionados à interferência da internet sobre a dinâmica da consulta e sobre a relação médico-paciente também são controversos. Pesquisadores ${ }^{13}$ observaram que entre 499 pacientes usuários da internet, apenas 177 respondentes a utilizavam para obter informações sobre saúde. Destes, $15 \%$ concordavam que os médicos deveriam lhes perguntar sobre a busca que realizaram na internet e, $65 \%$ dos pacientes achavam que os médicos deveriam indicar sites específicos da $W e b$ onde eles pudessem se informar adequadamente.

Com relação às pacientes mais bem informadas, e, possivelmente, mais questionadoras, emerge ainda a questão da perda da autoridade médica. Da análise das questões abertas observou-se que alguns profissionais temiam a perda de poder, conferido pelo conhecimento absoluto, do qual apenas o médico era detentor. Atualmente, com mais informação ao alcance do público, o médico é mais questionado e também divide a responsabilidade de suas condutas com seus pacientes ${ }^{6}$. Quanto aos profissionais que responderam que o conteúdo trazido da internet pelas pacientes não interferia na dinâmica da consulta, provavelmente compunham um grupo de médicos que já estabeleceram uma dinâmica adequada com as mesmas, independentemente de questionamentos ou de se sentirem testados em seus conhecimentos.

Da mesma forma, informações obtidas na internet e trazidas às consultas, sugeriram aos médicos interferências positivas e negativas quanto à relação médico-paciente, entretanto, predominaram aqueles que a julgaram negativa, o que discorda de dados de literatu$\mathrm{ra}^{14,15}$. O preconceito com relação a esta questão ficou evidente entre os profissionais de GI.

Alguns autores ${ }^{14}$ defendem que as informações obtidas na internet poderiam se associar à interação médico-paciente tradicional, pois forneceriam ao paciente embasamento adequado em determinado assunto médico e desta forma, a consulta poderia ser eficientemente gasta para redefinir informações ou responder questões. Também, em pesquisa anterior $^{15}$ se observou que a forma pela qual os médicos discutem com seus pacientes as informações trazidas da internet tem o potencial de afetar a evolução dos mesmos, incluindo a satisfação com as decisões e adesão aos tratamentos. Os sites ou portais de busca propiciam ainda trocas de experiências com outros indivíduos portadores da mesma patologia, o que poderia torná-los mais participativos.

A preocupação com implicações éticas e legais, entre $69 \%$ e $44 \%$ dos respondentes talvez reflita algum receio quanto ao envolvimento com práticas ilegais freqüentes na internet para obtenção de medicamentos controlados, ${ }^{16} \mathrm{Ou}$ ainda, demonstre que o médi- 
co não queira se tornar um mero "prescritor virtual” de medicações, assumindo responsabilidades sem o suficiente conhecimento de seu paciente. As prescrições médicas legais on line, devem ser abordadas como questão muito complexa uma vez que não pressupõe o contato direto com o paciente ${ }^{1}$.

Quanto ao uso da internet para tirar dúvidas ou orientações através de simples emails, os profissionais pesquisados não a consideraram prática que pudesse acarretar muitas implicações, mas não se verificou um consenso. Apesar de apenas $24 \%$ dos profissionais terem referido implicações econômicas relacionadas à realização de tais atividades sabe-se que os médicos não são reembolsados por estes serviços, situação esta que vem sendo observada por outros autores em vários países².

Diretamente associada à questão econômica de recebimento de honorários médicos está a questão da disponibilidade de tempo entre os profissionais. Tal questão foi largamente citada nos comentários escritos das questões abertas entre os profissionais dos quatro grupos, mais evidente, entretanto, entre os profissionais do grupo GII. Segundo muitos deles, a consulta tornou-se mais demorada o que dificultou ainda mais o dia-a-dia do profissional. Isto, para aqueles que, infelizmente, têm que atender um número muito grande de pacientes para obterem uma remuneração compatível com suas necessidades, representa implicação econômica negativa.

Apesar das evidentes vantagens dos serviços via internet, os médicos, que vêem cada vez mais aumentar sua demanda de tempo gasto com a medicina hesitam em aceitar responsabilidades que possam aumentar suas horas de trabalho ${ }^{17}$. Possivelmente, se forem adequadamente reembolsados eles encontrarão mais tempo para estas atividades. Nos Estados Unidos, alguns convênios de saúde passaram a reembolsar consultas realizadas por internet. Recebimento de exames, retornos e requisição de prescrições são de graça. Os gastos dos pa- cientes com as idas aos consultórios e com o estacionamento fazem com que os mesmos julguem uma forma adequada e menos onerosa de realizarem sua consulta médica ${ }^{3}$. Infelizmente, no Brasil a realidade ainda é diferente, pois não existem convênios de saúde dispostos a remunerar pelos serviços prestados on line e estudos nacionais sobre os diversos aspectos desta nova realidade ainda são poucos ${ }^{18,19}$.

Apesar de não se ter observado um predomínio de preocupações econômicas associadas ao agendamento de consultas via internet, esta poderia acarretar grande impacto econômico relacionado à estruturação informática do consultório e à adequação a diferentes formas de recebimento dos honorários decorrentes da marcação das mesmas ${ }^{2,3}$. Talvez a reticência observada entre alguns profissionais quanto a esta prática também se relacione ao pressuposto aumento de não comparecimentos, dada à facilidade de marcação, o que acarretaria horas ociosas do médico que aguardava pela realização da mesma e representaria implicações econômicas negativas. Por outro lado, a exposição da agenda do médico através de sites iterativos onerosos, facilitaria o comparecimento excessivamente freqüente de pacientes muito ansiosas, propiciando mais faltas aos serviços e dificultando a cobrança dos honorários pelos atendimentos prestados.

A possibilidade do agendamento de consultas representar um fator de exclusão ao acesso médico para aqueles que não possuem internet poderia ser verificada apenas se esta fosse a única maneira disponibilizada ao paciente. Esta prática foi pouco relacionada às questões éticas e legais que não foram comentadas nas questões escritas.

A predominância de associações das consultas on line para acompanhamento de pacientes crônicos com aspectos éticos e legais deve-se, provavelmente à ausência da fisicalidade. Os profissionais podem sentir-se receosos ao orientar, prescrever ou alterar o tratamento de pacientes sem reexaminá-los, ou 
confrontá-los face-a-face, uma vez que a relação virtual facilita a omissão de importantes informações por parte do paciente. Apesar de apenas $28 \%$ dos profissionais terem referido preocupações com as implicações econômicas decorrentes desta prática, ficam implícitas as questões de recebimento de honorários, além da necessidade da criação de sistemas que garantam sigilo e privacidade das informações trocadas, segundo as normas do CREMESP ${ }^{20}$.

Sobre a mudança da prática médica com a introdução da internet na medicina (Q13), a grande maioria dos profissionais respondeu que esta mudará, o que concorda com vasta literatura9,12. Entretanto, observou-se que alguns profissionais ainda a praticam "à moda antiga”. Na questão Q14, os motivos que justificavam o não uso da mesma foram que a consulta face-a-face facilita o diagnóstico e o tratamento, e que sua utilização influencia a administração do tempo destes profissionais. Da análise do grupo GI, observou-se ainda receio quanto às implicações éticas e legais entre esses profissionais, e quanto às interferências negativas que informações de má qualidade poderiam exercer na relação médico-

\section{REFERÊNCIAS}

1. Blum JD. Internet medicine and the evolving legal status of the physicianpatient relationship. J Leg Med. 2003; 24:413-55.

2. Sciamanna CN, Rogers ML, Shenassa ED, Houston TK. Patient access to US physicians who conduct internet or email consults. J Gen Int Med. 2007; 22 (3):378-81.

3 Stone JH. Communication between ph ysicians and patients in the era of Emedicine. Vasculitis Center and Johns Hopkins University School of Medicine, Baltimore, USA: N Engl J Med. 2007;356(24):2451-4. paciente. Apesar do uso freqüente da internet entre a maioria dos sujeitos da pesquisa, observou-se uma tentativa de resgate da prática da clínica médica, que, segundo os mesmos, é soberana, e impõe um exame físico além do contato direto com a paciente. $\mathrm{O}$ ato de receber, interpretar e responder exames ou simplesmente orientar pacientes on line, para a maioria, facilitaria a prática de uma medicina incompleta na qual seu principal eixo de sustentação estaria excluído.

A internet vai provocar profundo impacto na prática e administração da medicina. Médicos engajados em oferecer serviços de alta qualidade e forçados pela competição do mercado vão introduzir e-mails e Web sites para conduzirem serviços burocráticos e situações médicas comuns; serão obrigados a se atualizar cada vez mais e dividirão responsabilidades com seus pacientes, alterando a relação médico-paciente.

Os profissionais deste estudo estão se preparando para a transformação eletrônica, mas muitos ainda estão relutantes e receosos desta transformação que, de maneira geral, julgam de ocorrência iminente e inevitável.

4. Berquó ES, Souza JMP, Gotlieb SLD. Bioestatística. São Paulo: EPU; 1980; 325p.tabs.

5. Armitage P, Berry G, Matthews JNS. Statistical methods in medical research. 4,. ed. Blackwell Science Ltd. UK, 2002; 817 p. ilus.

6. Usher WT.Gold Coast general practitioners' recommendations of health websites to their patients.Education and Professional Studies, Griffith University, Gold Coast, QLD, Australia. Med J

Aust. 2007;187(2):82-3.

7. Johnson PT, Eng J, Rowell MR, Fishman EK. Evolving physician perception of world wide web education: 
2007 update and review of the literature. Acad Radiol. 2007 Sep;14(9):1092-101.

8. Martin S. Younger physicians, specialists use internet more. Can Med Assoc J. 2004; 170(12):1780.

9. Lowrey W, Anderson WB. The impact of Internet use on the public perception of physicians: A perspective from the sociology of professions literature. Health Commun. 2006; 19(2):125-31.

10. Cuenca AMB. O uso da internet por docentes da área de Saúde Pública no Brasil. [tese de doutorado]. São Paulo: Faculdade de Saúde Pública da USP; 2004; 124p.

11. Martinez AR, Vegas AA, de Cordoba JLDLF. Internet physician's offices: main reasons for consultation and differences with Primary Care. Rev Clin Esp. 2004; 204:198-201.

12. Umefjord G, Hamberg K, Malker H, Petersson G. The use of an Internetbased Ask the Doctor Service involving family physicians: evaluation by a web survey. Fam Pract. 2006; 23 (2):159-66.

13. Diaz JA, Sciamanna CN, Evangelou E, Stamp MJ, Ferguson T. Brief Report: what types of internet guidance do patients want from their physicians? J Gen Int Med. 2005; 20(8):683-85.
14. Biermann JS, Golladay GJ, Peterson $\mathrm{RN}$. Using the Internet to enhance physician-patient communication. J Am Acad Ortho Surg. 2006; 14(3):136-44.

15. Bylund CL, Gueguen JA. Physicianpatient conversations about internet cancer information. Psycho-Oncol. 2006; 15:189 Suppl.

16. Lineberry TW, Bostwick JM. Taking the physician out of "physician shopping": a case series of clinical problems associated with internet purchases of medication. Mayo Clin Proc. 2004; 79(8):1031-34.

17. Brown MS. Physicians on the internet: ambivalence and resistence about to give way to acceptance. Med Net.1998; 4:1921.

18. Carvalho Júnior, FF. A Internet e o pediatra. Rev. Paul. Pediatr. 1999; 17(3):150-53.

19. Huñis AP. Médicos e Internet. Inform Med.2000; 7:41-2.

20. CREMESP - Conselho Regional de Medicina do Estado de São Paulo. Resolução 97 de 20 de Fevereiro de 2001. São Paulo, 2001 [acesso em 28 de junho de 2007]. Disponível em http:// www.bioetica.org.br/legislacao/res_par/ integra/97_01.php.

Recebido em 28 de março de 2009. Modificado em 30 de julho de 2009. Aceito em 30 de novembro de 2009. 